\title{
Model and Simulation Study on Pressurizer Pressure System
}

\author{
Z.B. Xu, J. Wu, Z.T. Quan, X.S. Zhang, X.Q. Ma \\ School of Electric Power \\ South China University of Technology \\ Guangzhou, China \\ Guangdong Province Key Laboratory of Efficient and Clean Energy Utilization \\ China \\ Key Laboratory of Efficient and Clean Energy Utilization of Guangdong Higher Education Institutes
}

\begin{abstract}
A double-district equilibrium model of a nuclear power plant pressurizer dynamic characteristic was established through the approach of theoretical modelling simplifying. Moreover, the proposed model was examined in spray water disturbances and heating disturbances experiments by on-site simulator operating data. Compared the results of experiments at the proposed model with that of the simulator, two results agreed well with each other, which validate the proposed model of this paper.
\end{abstract}

Keywords-nuclear power plant; pressurizer; the double-district equilibrium model

\section{INTRODUCTION}

The pressurizer of nuclear power plant is an important component in the primary loop with a basic function as establishing and maintaining the pressure of primary system, to avoid coolant malfunction occurring within the boiling reactor volume. Thus the pressurizer function is crucial to the security of entire primary loop [1]. Moreover, as a buffer container of primary loop system, pressurizer restrains the serious fluctuations of water volume in primary loop system. As the pressurizer control includes pressure control and water level control, this article studied the pressure control system.

Pressurizer dynamic process is a complex non-linear process of time-varying, suffering disturbances, which challenge the establishment of a wholesome accurate mathematical model. Since the 1960s, a series of studies on pressurizer characteristics have been conducted, and different theoretic models have been set up [2]. At first, an equilibrium model was put forward, in which the liquid phase region and vapor region were assumed always at equilibrium state. This kind of model could reduce the number of parameters, simplifying the computation [3]. But this model could not set up the transfer function facilitate to control. However, the double-district equilibrium model this paper established was simplified further by the approach of centralized parameter method. At last, the state space model on pressure's changes was set up. By way of mechanism for modelling, the model has more universality.

\section{THE MODELLING PROCESS}

\section{A. The Main Parameters of the Pressurizer}

Electrical heating pressurizer was used commonly in current nuclear plant. The main design parameters of pressurizer in a nuclear power plant was shown in Table 1[4]:

TABLE I. THE MAIN DESIGN PARAMETER REGULATOR TABLE.

\begin{tabular}{|c|c|c|}
\hline Parameter & Unit & $\begin{array}{l}\text { Numerical } \\
\text { value }\end{array}$ \\
\hline Design pressure $p$ & Mpa & 15.5 \\
\hline Design temperature $t$ & ${ }^{\circ} \mathrm{C}$ & 360.0 \\
\hline Diameter $\mathrm{d}$ & $\mathrm{m}$ & 2.29 \\
\hline Total height $\mathrm{Ht}$ & $\mathrm{m}$ & 12.8 \\
\hline Water Volume V & $\mathrm{m}^{3}$ & 23.96 \\
\hline Internal volume VL & $\mathrm{m}^{3}$ & 39.75 \\
\hline Spray flow Wsp & $\mathrm{m}^{3} / \mathrm{s}$ & 0.0379 \\
\hline Electrical heat total power Qh & $\mathrm{kW}$ & 1600 \\
\hline $\begin{array}{l}\text { Steam temperature In steam chamber } \\
T_{\text {vap }}\end{array}$ & ${ }^{\circ} \mathrm{C}$ & 344.84 \\
\hline Saturated water Temperature $T_{l i q}$ & ${ }^{\circ} \mathrm{C}$ & 344.76 \\
\hline Fluctuant water Temperature $T_{s u}$ & ${ }^{\circ} \mathrm{C}$ & 344.71 \\
\hline
\end{tabular}

B. Mathematical Modelling Based on Pressure Characteristics

The following assumptions were made based on the pressurizer characteristics in order to establish a reasonable concise mathematical model:

The whole pressurizer was always kept in thermal equilibrium. The thermal parameters in each control zone were constant thought as the lumped parameters. In this model, the compressibility of water was ignored; two-phase state was close to equilibrium under transient and steady state conditions. There was no energy exchange between the fluid and the surroundings [5].

According to double-district equilibrium model, the three conservation equations were as follows:

Mass conservation equation was: 


$$
\frac{d m_{f}}{d t}+\frac{d m_{g}}{d t}=W_{s u}+W_{s p}-W_{s a}
$$

Energy conservation equation was:

$m_{f} \frac{d h_{f}}{d t}+m_{g} \frac{d h_{g}}{d t}+h_{f} \frac{d m_{f}}{d t}+h_{g} \frac{d m_{g}}{d t}-V \frac{d p}{d t}=W_{s u} h_{x 1}+W_{s p} h_{f}-W_{s a} h_{g}+Q_{h}$

Volume conservation equation:

$$
m_{f} \frac{d v_{f}}{d t}+m_{g} \frac{d v_{g}}{d t}+v_{f} \frac{d m_{f}}{d t}+v_{g} \frac{d m_{g}}{d t}=0
$$

In the equations above: $m$ - the coolant mass in the pressurizer; V_- the volume of pressurizer; ${ }^{W_{s u}}$ — the mass

of spray flow; $W_{s a}$ — the safety valve flow; $\mathrm{p}$ — the pressure of pressurizer; $v \_$- specific volume; $h-$ _ specific enthalpy; $\mathrm{Qh}$ —electrical heating power. Footer $\mathrm{f}$ liquid phase. Footer g represents vapour phase; and

$$
h_{x 1}= \begin{cases}h_{s u} & \text { plus } \\ h_{1} & \text { minus }\end{cases}
$$

According to equation (1), equation (4) was obtained.

$$
\frac{d m_{f}}{d t}=W_{s u}+W_{s p}-W_{s a}-\frac{d m_{g}}{d t}
$$
(6):

Equations (2) 、 (3) could be simplified into equations (5)

$$
\begin{aligned}
& \frac{d p}{d t}\left(m_{f} \frac{d h_{f}}{d p}+m_{g} \frac{d h_{g}}{d p}-V\right)+h_{f} \frac{d m_{f}}{d t}+h_{g} \frac{d m_{g}}{d t} \\
& =W_{s u} h_{x 1}+W_{s p} h_{f}-W_{s a} h_{g}+Q_{h} \\
& \frac{d p}{d t}\left(m_{f} \frac{d v_{f}}{d p}+m_{g} \frac{d v_{g}}{d p}\right)+v_{f} \frac{d m_{f}}{d t}+v_{g} \frac{d m_{g}}{d t}=0
\end{aligned}
$$

Equations (5)、 (6) was simplified into equations (7) (8):

$$
\begin{aligned}
& M_{h} \frac{d p}{d t}+h_{f g} \frac{d m_{g}}{d t}=W_{s u} h_{x 1}+W_{s p} h_{f} \\
& -W_{s a} h_{g}-\left(W_{s u}+W_{s p}-W_{s a}\right) h_{f}+Q_{h} \\
& M_{v} \frac{d p}{d t}+v_{f g} \frac{d m_{g}}{d t}=-\left(W_{s u}+W_{s p}-W_{s a}\right) \cdot v_{f} \\
& M_{h}=m_{f} \frac{d h_{f}}{d p}+m_{g} \frac{d h_{g}}{d p}-V \\
& M_{v}=m_{f} \frac{d v_{f}}{d p}+m_{g} \frac{d v_{g}}{d p} \\
& h_{f g}=h_{g}-h_{f} \\
& v_{f g}=v_{g}-v_{f}
\end{aligned}
$$

At last, the following equation was obtained:

$$
\begin{aligned}
& \frac{d p}{d t}=\left\{W_{s u}\left[v_{f g}\left(h_{x 1}-h_{f}\right)+h_{f g} v_{f}\right]+W_{s a}\left[v_{f g}\left(h_{f}-h_{g}\right)-h_{f g} v_{f}\right]\right. \\
& \left.+W_{s p} h_{f g} v_{f}+v_{f g} Q_{h}\right\} /\left(v_{f g} M_{h}-h_{f g} M_{v}\right)
\end{aligned}
$$

The serious fluctuations of pressure of the primary loop were not allowed during steady-state operation of the unit. Thus this paper assumed that the changes of pressure are small while at small step changes [6]. Pressurize pressure fluctuant range was $15.4 \mathrm{MPa}<\mathrm{P}<15.6 \mathrm{Mpa}$ after the introduction of the steam turbine load $-10 \%$. Water and vapour's parameters was regarded unchanged and the rate of change was constant in such a small pressure fluctuant range [7]. The value of parameters was shown in Table2.

TABLE II. REGULATOR STEP CHANGE OF PARAMETERS.

\begin{tabular}{|l|l|}
\hline Parameter & Numerical value \\
\hline The initial pressure & $p_{0}=15.5 \mathrm{MPa}$ \\
\hline $\begin{array}{l}\text { Fluctuations water specific } \\
\text { enthalpy }\end{array}$ & $h_{x 1}=1630.23938 \mathrm{~kJ} / \mathrm{kg}$ \\
\hline Saturated water hematocrit & $v_{f}=0.001683 \mathrm{~m}^{3} \cdot \mathrm{kg}^{-1}$ \\
\hline $\begin{array}{l}\text { Specific volume of saturated } \\
\text { steam }\end{array}$ & $v_{g}=0.009810 \mathrm{~m}^{3} \cdot \mathrm{kg}^{-1}$ \\
\hline $\begin{array}{l}\text { Specific enthalpy of saturated } \\
\text { water }\end{array}$ & $h_{f}=1630.723877 \mathrm{~kJ} \cdot \mathrm{kg}^{-1}$ \\
\hline $\begin{array}{l}\text { Specific enthalpy of saturated } \\
\text { steam }\end{array}$ & $h_{g}=2600.295654 \mathrm{~kJ} \cdot \mathrm{kg}^{-1}$ \\
\hline $\begin{array}{l}\text { Saturated water hematocrit rate } \\
\text { of change }\end{array}$ & $d v_{f} / d p=5.25 \times 10^{-11}$ \\
\hline $\begin{array}{l}\text { Saturated steam specific volume } \\
\text { rate of change }\end{array}$ & $d v_{g} / d p=-1.03 \times 10^{-9}$ \\
\hline $\begin{array}{l}\text { Rate of change of the specific } \\
\text { enthalpy of saturated water }\end{array}$ & $d h_{f} / d p=3.95 \times 10^{-5}$ \\
\hline $\begin{array}{l}\text { The rate of change of specific } \\
\text { enthalpy of saturated steam }\end{array}$ & $d h_{g} / d p=-3.02 \times 10^{-5}$ \\
\hline
\end{tabular}

These parameters were substituted into equation (13).Then the equation of pressurizer pressure changing over time was obtained:

$$
\begin{aligned}
& \frac{d p}{d t}=2.887 \times 10^{-3} W_{s u}+2.893 \times 10^{-3} W_{s p} \\
& -0.01687 W_{s a}+1.444 \times 10^{-8} Q_{h}
\end{aligned}
$$

The transfer function of the valve should be added in actual control when considering the control during the operation of nuclear power plants require valve and flow must be controlled by valve opening. Since valves in PWR pressurizer were mostly equal percentage valves, a representative curve of the valve was chosen in this paper [8], and its transfer function was:

$$
\frac{\mathrm{W}(\mathrm{s})}{\mathrm{L}(\mathrm{s})}=\frac{1}{1+T_{1} s}
$$

Due to the distance from the valve to the pressurizer inlet and outlet, there is a delay of the flow control. Finally the transfer function of first pure delay objects was: 


$$
G_{1}(\mathrm{~S})=\frac{K}{1+T_{1} S} \bullet e^{-\theta S}
$$

$\mathrm{T} 1$ is the time constant of object; $\mathrm{K}$ is the proportionality coefficient and $\theta$ refers to the lag time of object [9] in the formula above.

\section{Simulation Test of Pressurizer Pressure CHARACTERISTICS}

In order to verify the correctness and effectiveness of the double-district equilibrium model, its simulation model was established. Under the premise of ensuring model's accuracy, some simplifying assumptions and numerical processing were made. This paper also did parameter tuning with reference to a nuclear power plant's operating data.

Taking the pressurizer of a nuclear power plant as an example, the water flow disturbance tests were conducted by the approach of establishing the simulation test system of its pressure characteristics. They were verified separately since sprinkler water flow and electric heater power are controllable variables. And the result was compared with the result of the nuclear power plant simulator.

At the very beginning, the unit load was kept in $100 \%$ working condition. And the opening degree of RCP001VP spray valve changed from $1 \%$ to $5.2 \%$. At the same time, the opening degree of RCP002VP maintained at $1 \%$. In other words, cold segment spray flow increased from $0.06 \mathrm{~kg} \cdot \mathrm{s}-1$ to $1.03 \mathrm{~kg} \cdot \mathrm{s}-1$. The pressurizer pressure control system was not performed, namely, the other valves were kept the same, and the proportion heaters were all closed. Its pressure variation curve within 3 minutes was shown in Figure2.

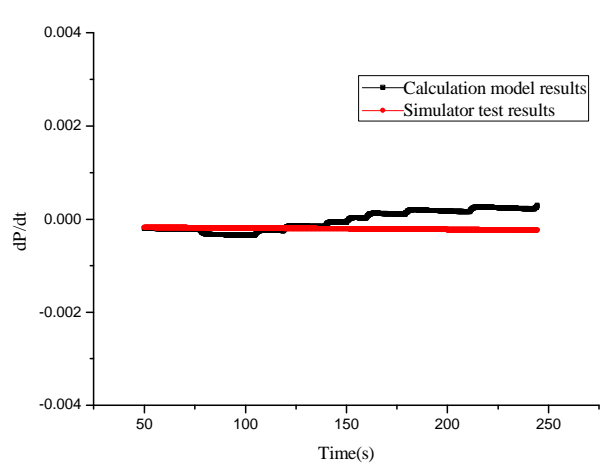

FIGURE 1. THE CURVE DIAGRAM OF THE PRESSURIZER'S PRESSURE LEVEL IN 2\% WORKING CONDITIONS

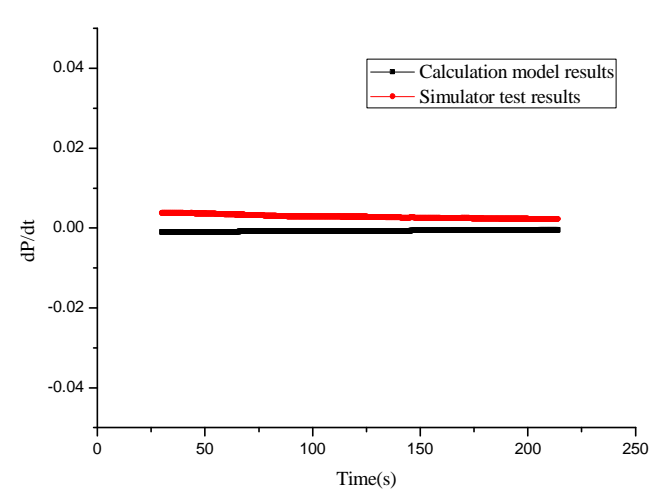

FIGURE 2. THE CURVE DIAGRAM OF PRESSURIZER'S PRESSURE LEVEL IN 6.2\% WORKING CONDITIONS.

As it can be seen from Figure1 and 2, when RCP001VP spray valve opening was increased, the cooling water flow increased. The pressurizer pressure decreased monotonically if the pressure control system was not performed. The pressure fluctuation was very small because the changes of valve opening were very small. The results of the model that this paper proposed agreed well with that of the nuclear power plant simulator.

RCP001VP opening degree was increased to $13.5 \%$ in the case above while the rest valves' opening remained unchanged to verify the accuracy of the model further. The final pressurizer pressure variation curve was shown in Figure 3.

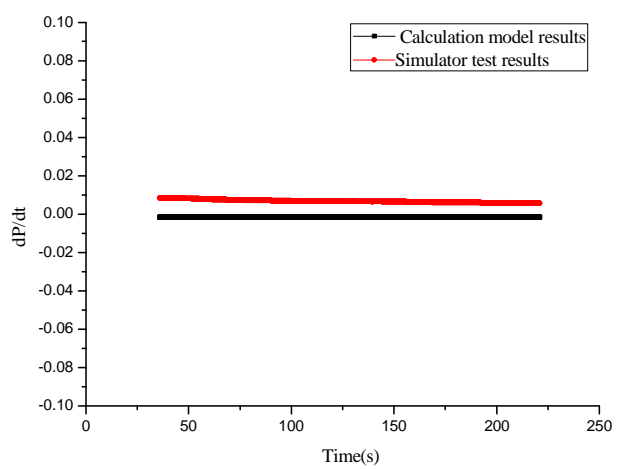

FIGURE 3. THE CURVE DIAGRAM OF PRESSURIZER'S PRESSURE LEVEL IN $14.5 \%$ WORKING CONDITIONS.

As it can be seen from the validation process of sprinkler flow disturbance experiment, the lowering speed of the pressurizer pressure increased while spray flow increased. And slope of the pressure decrease fitted well with the slope calculated by the model this paper proposed.

The model was examined in heating disturbances experiments to verify the correctness of the model further. Spray valve of Nuclear Simulation Unit was adjusted to manual control, which was disconnected from the control system. Open one, two and three electric heaters in turn while the opening degree of the two main spray valves was kept in 
$1 \%$. The changes of the pressurizer pressure in 3 minutes were obtained as follows.

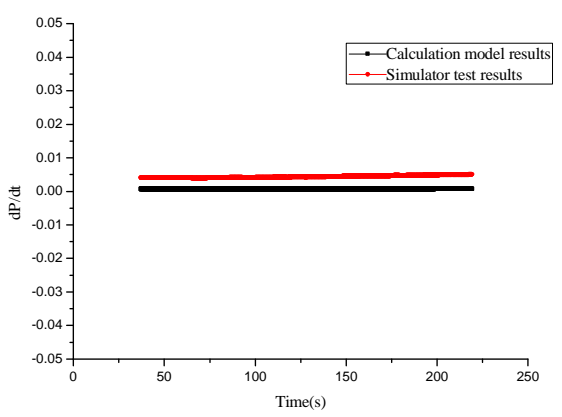

FIGURE 4. PRESSURIZER PRESSURE LEVEL CONDITIONS WITH ONE ELECTRIC HEATER OPEN.

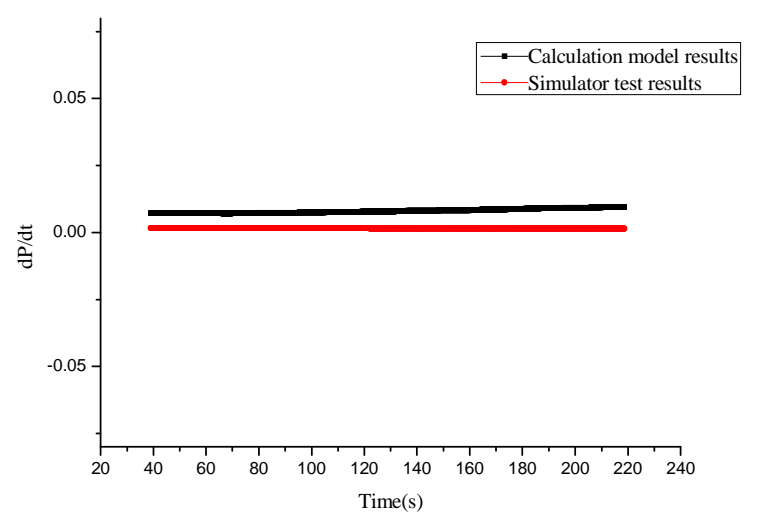

FIGURE 5. PRESSURIZER PRESSURE LEVEL CONDITIONS WITH TWO ELECTRIC HEATER OPEN.

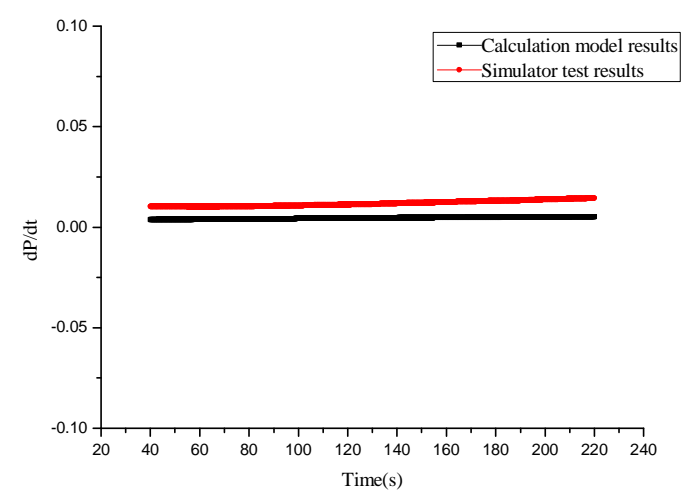

FIGURE 6. PRESSURIZER PRESSURE LEVEL CONDITIONS WITH THREE ELECTRIC HEATER OPEN.

As it can be seen from Figure 4, 5 and 6, the pressure of pressurizer increased rapidly when heating power increased. When the spray valve opening was small and stayed the same, the flow rate of fluctuations tube increased and water entered the pressurizer reversely, resulting in pressurizer outsurge. The tendency of pressurizer pressure was almost linear during the experiments. And the results of the proposed model agreed well with that of the simulator.

The proposed model was proved to be right through the comparison. The miscalculation of this model is small. And this model has a second-order inertia and a simple form; meanwhile it can be controlled easily.

\section{CONCLUSIONS}

(1)The nuclear power plant pressurizer mathematical model of the dynamic characteristics was established based on the laws of physics. This model could reflect the relationship among cold segment water, the electric heating power and pressure changes of the pressurizer. The parameters can be tuned according to the actual data of nuclear power plants, which shows this model is a practical application.

(2) The nonlinear model was converted to a second inertia model. Thus it was more conducive to be controlled by simplifying the model. Furthermore, this paper verified the validity and correctness of the model adequately by adjusting RCP001VP valve opening and heating power in the simulation experiment.

\section{ACKNOWLEDGEMENTS}

This work was supported in part by Guangdong Province Key Laboratory of Efficient and Clean Energy Utilization (NO. 2013A061401005), The Fundamental Research Funds for the Central Universities (NO. 2014ZZ0010) and The National Natural Science Foundation of China (Grant No. 51206054)

\section{REFERENCES}

[1] Guangdong Nuclear Power Training Center. 900MW pressurized water reactor nuclear power plant systems and equipment [M]. Atomic Energy Press, 2004.

[2] Baron R. C. Digital Simulation of a Nuclear Pressurizer. Nuclear Science Journal. 1982

[3] Redfield J A. Pressurizer Performance during Loss of Load Test at Shippingport: Analysis and Test. Nuclear Application. 1986

[4] Zang Xinian. Systems and equipment in nuclear power plants [M] Beijing: Tsinghua University Press, 2010.

[5] Zang Xinian, Guo Yuewu. Nuclear Power Plant Simulator regulator mathematical model [J] Energy Science and Technology, 1993, 05: 439445

[6] Wang Peihong, Cheng Maohua, Si Fengqi, Guo Zhonghua. Thermodynamic properties of water and water vapor IFC generic formula calculation software [J] Turbine Technology, 1995, 03: 163-167 $+188$

[7] Fang Jiuchun. Pressurizer control method study of AP1000 nuclear power plant based on OVATION [D] .Harbin Engineering University, 2011.

[8] Nie Chunyan, Zhang Meng. MATLAB and LabVIEW simulation technology and application examples [M]. Beijing: Tsinghua University Press, 2008.

[9] Zhou Xingji. Equal percentage valve control strategies in a first-order delay System [J]. Chemical Automation and Instrumentation, 2009(05) 